\title{
LA JUVENTUD RURAL EN AMERICA LATINA \\ Y EL CARIBE: \\ CONDICIONES DE VIDA \\ Y PARTICIPACION EN EL DESARROLLO
}

M. Cristina Osorio L.

Publicación de FAO, Oficina Regional para América Latina y el Caribe con motivo de la celebración del Día Mundial de la Alimentación y en el Año Mundial de la Juventud, pp. 104, 1985.

Este informe fue confiado al sociólogo haitiano señor Welnes Benjamín, Consultor de FAO y constituye una respuesta a la preocupación de Naciones Unidas por el contingente joven de los países de esta región.

La asincronía observada entre los ritmos de crecimiento de la población en América Latina y el Caribe y el aumento de las tasas de producción agrícola y ganadera, constituye un desafío; urge por lo tanto, buscar mecanismos que permitan satisfacer adecuadamente las necesidades de alimentación y empleo en los próximos años, como en general, de todas las necesidades básicas de la población, incluyendo aquí la problemática que presenta la juventud rural.

\section{Capítulo I}

LAS CATEGORIAS DE ANALISIS

PARA LA APRENSION CONCEPTUAL

DE LA JUVENTUD

Se destaca la diversidad de criterios existentes para definir esta etapa de la vida, situación que limita las posibilidades de análisis comparativo entre los países de la región. Esta dificultad se acrecienta al introducir la variable Area de residencia, ya que la juventud urbana y la rural tienen características muy diferentes, en gran medida determinadas por el proceso de modernización.

El autor distingue 3 grupos o categorías de jóvenes:

a) la juventud rural.

b) la juventud urbana de sectores marginales $y$

c) la juventud urbana de sectores medios altos, observándose la mayor distancia entre las categorías a) y c), determinadas por la incidencia del medio (educación, influencia de los medios de comunicación de masas, velocidad de la modernización, contenidos incorporados a los procesos de socialización, etc.) y por factores intervinientes como la alimentación, la salud, etc. 
Resalta también, un punto ya analizado por Aldo Solari, como es la diferenciación entre Juventud Urbana y Rural, en cuanto a la asunción de responsabilidades sociales y económicas; es usual que entre los menores residentes en áreas rurales, apenas superada la etapa pre-escolar se incorporen en alguna medida a la fuerza del trabajo, particularmente entre los componentes de comunidades indígenas. Este hecho, como también la paternidad temprana, aceleran el paso de joven a adulto, sin que cronológicamente tenga esto una definición precisa. Por otra parte, la juventud rural más aislada de las influencias de la modernización, se mantiene apegada a la tradición, por ende, a la fuerte influencia de la familia, particularmente entre aquellos países menos desarrollados de la región.

\section{Capítulo II}

LA GRAN CIUDAD: UN ESPEJISMO PARA LA JUVENTUD

Las razones de este magnetismo, siendo muy diversas, pueden agruparse en económicas y socio-culturales, incluyendo en este último sub-conjunto, las aspiraciones educacionales y la búsqueda de ampliación de perspectivas familiares. Sin embargo, un análisis más profundo, nos permite visualizar que en los últimos 30 años se ha producido un deterioro de las condiciones de vida en el campo, producto de la sub-división de la tierra, del sub-empleo y del empobrecimiento de las tierras, ya sea por erosión o por sistemas inadecuados de explotación. Por otra parte, con la introducción de las agroindustrias, se ha producido una especie de proletarización del campesino, situación que acelera el proceso de desarraigo, particularmente entre los jóvenes. A su vez, ésta ha producido en el seno de las grandes ciudades un aumento considerable del sector terciario.

\section{Capítulo III}

LA PARTICIPACION DE LA JUVENTUD EN LOS PROCESOS DE DESARROLLO SOCIO-ECONOMICO EN EL SECTOR RURAL DE AMERICA LATINA Y EL CARIBE

Destaca el informe que toda preocupación que pueda tenerse por un grupo social determinado, en este caso la juventud rural, carece de proyección si se orienta en forma aislada, puesto que "la opción de soluciones de problemas que afectan a un grupo social específico suele comprometer al conjunto de relaciones que definen la situación anterior" (pp. 50). Lo sensato, por lo tanto, es favorecer la inserción de este segmento poblacional dentro del macro sistema. Para ello el contexto social, económico y político debe ofrecer a la juventud posibilidades reales de participación en el proceso de desarrollo, al mismo tiempo, los actores sociales deben intentar cambios orientados hacia una superación personal, de manera tal, que les permita asumir roles más activos dentro de su medio, buscando paralelamente, aminorar las diferencias de oportunidades que tienen ellos en relación a la de los 
jóvenes residentes en las áreas urbanas. En América Latina y el Caribe, la población joven económicamente activa residente en áreas rurales representa el $41 \%$, destacándose que este promedio difiere significativamente de un país a otro, como también si se estudia el tipo de actividades agrícolas en las que participan los jóvenes. Queda en claro sí, la existencia de una correlación significativa entre el porcentaje de población joven que labora en el campo y el grado de desarrollo del país, incidiendo aquí las tasas de natalidad, de urbanización, como también la capacidad de absorción y retención que tienen los sistemas escolares y la esperanza de vida alcanzada por cada país.

\section{Capítulo IV}

LAS PERSPECTIVAS SOCIOECONOMICAS DE LA JUVENTUD RURAL

Las políticas de redistribución de la tierra en la región, se han canalizado a través de distintos procedimientos de reforma agraria, más algunos tipos de créditos agrícolas y de políticas de precios y subsidios, todos los cuales han mostrado deficiencias y en último término han favorecido selectivamente a algunos sectores. Tal vez el mayor problema, dice relación con la formación de un conglomerado de pequeños propietarios que en definitiva han resultado incapaces para producir una reactivación de la producción y para convertir la agricultura en un sector dinámico y de acumulación. Se observa entonces, que la solución de los problemas de la juventud rural, no parece resolverse por la vía de la reforma agraria. Es evidente en cambio, que no han sido suficientemente valorados los efectos positivos que podría tener para el desarrollo del sector agrícola, la formación de asociaciones que en el plano económico permitan mejorar la productividad, obtener con mayor factibilidad créditos agrícolas y ampliar los canales de comercialización de los productos.

En el plano político-social, estas organizaciones podrían llegar a constituir grupos de presión, alcanzando así una mayor participación en las orientaciones políticas y económicas que se apliquen al sector. En síntesis, la formación de organizaciones en las que participe la juventud rural abre una vía concreta para el logro de un real nivel de desarrollo agropecuario.

\section{Capítulo V}

DEL DIAGNOSTICO A LA ACCION EN FAVOR DE LA JUVENTUD

En este último capítulo y a partir de las Estrategias Generales de faO para el desarrollo rural, acordadas en Roma en el año 1979, se proponen líneas generales de acción que sirvan de base a las acciones que cada país requiera, dada la diversidad de condiciones observables en la región.

Hay sin embargo, tres puntos claves y aplicables a todos los países. El primero dice relación con la necesidad de mejorar y profundizar el conocimiento existente 
sobre la juventud, antecedente indispensable para abordar los dos siguientes; estos se refieren al mejoramiento de la calidad de vida y al incremento de oportunidades para participar activamente en el desarrollo del país, por parte de los jóvenes asentados en áreas rurales.

Se destaca aquí la imperiosa participación que le cabe en el logro de estos 3 objetivos, a los gobiernos de los países de la región, quienes junto a los actores sociales y con el apoyo externo de organismos internacionales deberían adoptary ejecutar proyectos que favorecieran real y objetivamente las transformaciones económicas y sociales que el agro requiere.

Este completo informe de la situación que vive hoy la juventud rural de la región, ofrece además dos Anexos, uno formado por 7 cuadros que entregan información comparativa sobre: densidad de población, sectores donde se desenvuelve la población económicamente activa, migración rural-urbana, composición del PIB, significación de la población joven económicamente activa según área rural-urbana y distribución de los analfabetos que conforman la población joven del sector rural en los distintos países de la región.

El segundo Anexo ofrece una síntesis de las Estrategias Generales de la FAO para el Desarollo Rural, acordadas en Roma en 1979.

La lectura del Informe, que sucintamente hemos presentado, ofrece al lector una visión global de la realidad de la región. Sin pretenciones de ser exhaustivo, muestra a grandes pinceladas la relación existente entre los ritmos de crecimiento poblacional, y las posibilidades que ofrece la región de satisfacer sus demadas. Asimismo, destaca que se observa frente al retraso del sector rural, desarraigo del campesino y la falta de perspectivas que se le ofrece a los jóvenes que permanecen en el agro, lo cual incide en que cada país debe enfrentar el proceso de modernización.

Desde el punto de vista sociológico, plantea inquietudes y vacíos de conocimiento que motivan a su estudio. 